\title{
COMPARISON OF HOT DUCTILITY BEHAVIOR OF MICROALLOYED STEELS WITH DIFFERENT B-, CR-, NI- AND TI-CONTENT
}

\author{
1,2Marina GONTIJO, ${ }^{2}$ Christian HOFLEHNER, ${ }^{3}$ Sergiu ILIE, ${ }^{3}$ Jakob SIX, ${ }^{2}$ Christof SOMMITSCH \\ ${ }^{1}$ K1-MET GmbH, Linz, Austria, EU, marina.gontijo@k1-met.com \\ ${ }^{2}$ Institute of Materials Science, Joining and Forming, Graz University of Technology, Graz, Austria, EU, \\ christian.hoflehner@tugraz.at, christof.sommitsch@tugraz.at \\ ${ }^{3}$ voestalpine Stahl Linz GmbH, Linz, Austria, EU, sergiu.ilie@voestalpine.com, jakob.six@voestalpine.com
}

https://doi.org/10.37904/metal.2021.4140

\begin{abstract}
The continuous casting process requires permanent investigation and innovative improvements due to its large application in steel production. A good hot ductility behavior is essential to avoid the formation of defects during slab casting. The behavior of two low alloyed steels, with different compositions in $\mathrm{B}-, \mathrm{Cr}-, \mathrm{Ni}$ - and Ti-content, was compared to understand the features that might bring improvements in hot ductility, and consequently reduce the occurrence of defects. The first alloy investigated presents a low content of all elements and the second has a composition with a higher fraction of the alloying elements referred to. Hot tensile tests after in situ melting of the samples were performed to reveal the hot ductility behavior of the each microalloyed steel. The results of final reduction of area showed a much better ductility of the second steel, alloyed with higher B, $\mathrm{Cr}, \mathrm{Ni}$ and Ti-content, in comparison to the first. Initial microstructure analysis was performed as a means of better evaluating the effects of the temperatures and strain rate applied in both steels. Furthermore, precipitation kinetics of both steels were calculated using the MatCalc software, determining the expected mean radius, number density and phase fraction of the predicted precipitates. Possible reasons for the changes seen experimentally are discussed based on both, simulations and microstructure analysis.
\end{abstract}

Keywords: Continuous casting, low alloyed steel, hot ductility, hot tensile test, precipitates

\section{INTRODUCTION}

The occurrence of internal and surface cracks during the straightening operation of the continuous casting process is a major concern in this steelmaking process since it can reduce quality and increase costs [1,2]. The susceptibility to such cracking is evaluated through the hot ductility behavior of the steel, which usually presents its minimum in the range of 700 to $1,000{ }^{\circ} \mathrm{C}$, which also coincides with the temperature range at which straightening usually takes place [3-5]. The evaluation of the ductility at higher temperatures for different steel grades is thus essential.

The determination of the hot ductility curve is very useful for prediction of cracking in new steel grades and for implementing necessary adjustments to the industrial process [3]. The data for the curve is provided by performing hot tensile tests and subsequent determination of the reduction of area (RA) of the samples ruptured [2,6]. Values below $40 \%$ are considered too low and undesirable [5].

To improve some steel properties, alloying elements such as $\mathrm{Mn}, \mathrm{Ti}, \mathrm{B}, \mathrm{Al}, \mathrm{V}$ and others are usually added [7]. This addition, which can promote precipitation, combined with the ferrite films formed at grain boundaries during the phase transformation, can be the reason for the crack initiation $[4,6]$.

In the present work, two different low alloyed steels are tested at various temperatures, after heating the samples until the melting temperature is reached before cooling, as a means of reproducing the continuous 
casting process as closely as possible. The strain rate chosen for the hot tensile test is close to that for the industrial operation [5]. As a result of the different quantities of alloying elements used, the behavior of the two steels shows a relevant disparity, which will be explored. The possible reasons for the different performances are discussed based on the experimental and simulation results.

\section{MATERIALS AND METHODS}

The composition of the two chosen low alloyed steels analyzed is described in Table 1. The named steel number 1 has low carbon content and no significant quantity of any other alloying element. The steel number 2 has more alloying elements, such as $\mathrm{B}, \mathrm{Cr}, \mathrm{Ni}$ and $\mathrm{Ti}$, and also both lower sulfur content and more vanadium.

Table 1 Chemical composition in wt\%

\begin{tabular}{|c|c|c|c|c|c|c|c|c|c|c|c|}
\hline & C & B & Cr & Ni & Ti & Mn & V & Al & P & S & N \\
\hline $\mathbf{1}$ & 0.079 & 0.0002 & 0.280 & 0.028 & 0.014 & 1.67 & 0.004 & 0.051 & 0.013 & 0.0051 & 0.0052 \\
\hline $\mathbf{2}$ & 0.087 & 0.0024 & 0.950 & 0.470 & 0.027 & 1.64 & 0.107 & 0.052 & 0.0094 & 0.0005 & 0.0051 \\
\hline
\end{tabular}

The samples were machined with equal geometry for both steels, in dog-bone shape and axis parallel to the rolling directions, as shown in previous work [8]. Experiments were performed in an in-house built thermomechanical simulator, the BETA 250-5. It can produce a vacuum atmosphere, heat the samples until the melting point with an inductive heating and perform tensile tests at high temperatures after the solidification.

Samples were held by the upper tension arm of the machine, which deals with the displacement in the vertical direction. The lower part of the specimen is fixed and supported to compensate for the thermal expansion [8].

The temperature during the thermal cycle was measured by a thermocouple spot welded in the center of the sample. The samples were heated until melting, measured around $1450{ }^{\circ} \mathrm{C}$, and kept at this point for $90 \mathrm{~s}$ to ensure the dissolution of precipitates, bringing the tested material closer to the state existent after the continuous casting. Subsequently the specimens were cooled down to the test temperature chosen and held for $10 \mathrm{~s}$ before straining was initiated. Test temperatures were varied between 650 and $1,100{ }^{\circ} \mathrm{C}$, and the strain rate applied was constant and equal to $10^{-3} \mathrm{~s}^{-1}$. The sample fracture surface area was measured for each condition applied and the reduction of area was calculated. With the values obtained, the ductility curves for both materials were plotted.

Thermokinetic simulations were performed using the MatCalc software (version 6.02) to predict the precipitation behavior [9]. Equilibrium calculations were also carried out to determine the phase diagram, which indicates the precipitates that are expected for each of steel. The mean radius, number density and phase fraction calculations were made only for the higher temperatures $\left(80{ }^{\circ} \mathrm{C}\right.$ and above) to avoid the two-phase region where ferrite and austenite are simultaneously present, which is not yet precisely modelled.

The simulations considered the nucleation and growth of precipitates at grain boundaries $(\mathrm{gb})$ and dislocations (d). In the steel number 1, AIN (gb) and MnS (d) are expected to be formed, as well as AIN at MnS [10, 11]. In steel number 2, BN, Ti(C,N), MnS and other carbides (M6C, M7C3 and M23C6) were first considered, at grain boundaries and dislocations $[1,12,13]$. Due to a very low phase fraction of MnS and the other carbides (lower than $10^{-12} \%$ ), they were not considered for the final evaluations.

Initial microstructure analyses were also performed on the tested samples. The samples were cut in the length direction, polished, and etched with $3 \%$ Nital. First observations were after polishing, before etching, for qualitative analysis of porosity. They were subsequently etched and observed once more for analysis of the structures present.

The results from experiments and simulations were compared to a further understanding of the behavior of the steels independently and in comparison. 


\section{RESULTS AND DISCUSSION}

The hot ductility curve was determined for both alloys by applying the strain rate that correlates to the continuous casting, $10^{-3} \mathrm{~s}^{-1}$, at different temperatures in the range of 650 to $1,100{ }^{\circ} \mathrm{C}$. Curves are shown in Figure 1. The results for the steel number 1 , which have been partially published [8], show a ductility minimum between 850 and $700^{\circ} \mathrm{C}$, which is determined by the reference value of $40 \%$, indicated. As for the steel number 2 , the ductility seen is higher at all points, with its lowest at $700{ }^{\circ} \mathrm{C}$ and no clear ductility trough formed, never reaching the minimum of $40 \%$ of reduction of area.

These results indicate an improved hot ductility behavior with the addition of the alloying elements mentioned, especially $\mathrm{B}$ and $\mathrm{Ti}$, and the lower $\mathrm{S}$ content. Boron can move the ductility trough to lower temperatures by delaying austenite/ferrite transformation during cooling and improve ductility when it segregates to grain boundaries, repelling $S$ and occupying vacancies $[3,14,15]$. However, the formation of $B N$ at austenite grain boundaries can be a reason for crack initiation. The titanium addition is thus also beneficial, since it can build $\mathrm{TiN}$, which precipitate earlier and dispersively, leaving less $\mathrm{N}$ available for the formation of $\mathrm{BN}[3,14]$. TiN can also be nucleation sites for other precipitates, reducing the pinning effect of precipitates at grain boundaries, thus improving ductility [14]. Furthermore, when the Ti/N ratio is high enough, as it is for the second steel, the ductility has been seen to be improved [16,17].

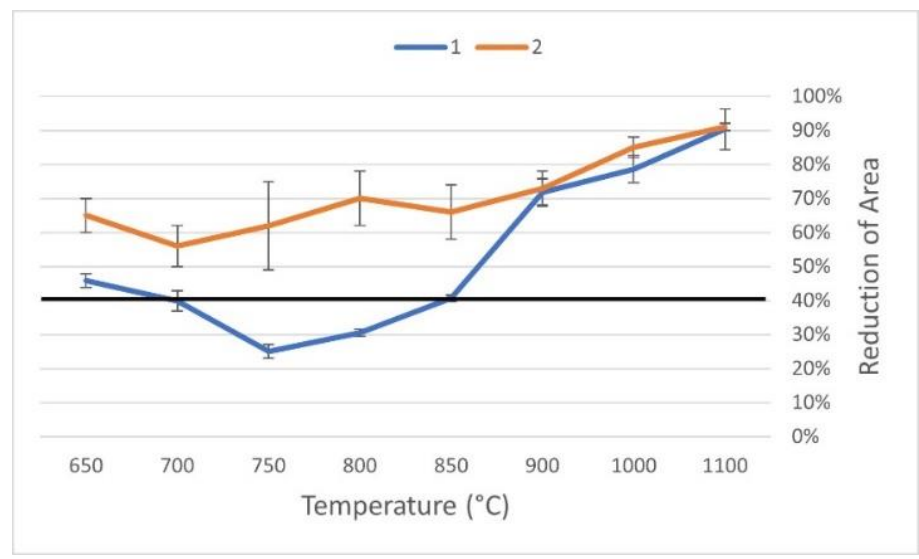

Figure 1 Reduction of area at different test temperatures for steel grades 1 and 2

Microstructure analyses of the samples from the steel number 1 are exemplified in Figure 2. Above $900{ }^{\circ} \mathrm{C}$ it showed recrystallized grains and some deformation induced ferrite formed in the grains, both linked to the good ductility seen at this range. Below $900{ }^{\circ} \mathrm{C}$ until $750{ }^{\circ} \mathrm{C}$, grains were larger and ferrite films were present at the boundaries, a fact that can account for the reduction in ductility, since the strain concentrates at the softer phase (ferrite) and cracks initiate more readily. At this temperature, the cracks were seen to initiate and follow the grain boundaries, typical to a brittle fracture. At $700{ }^{\circ} \mathrm{C}$ and lower, the ferrite amount was higher and above that considered critical for ductility and bringing a ductility recovery [18].

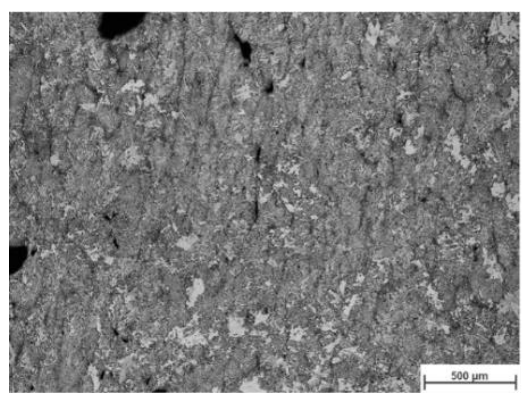

(a)

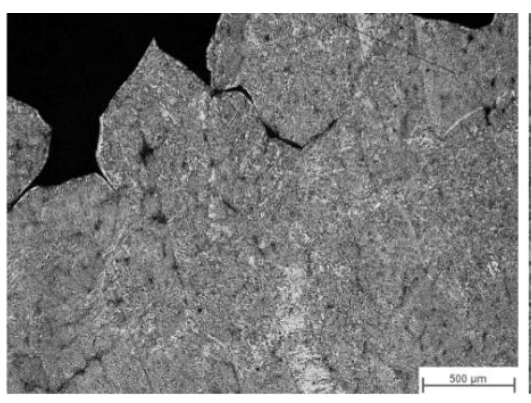

(b)

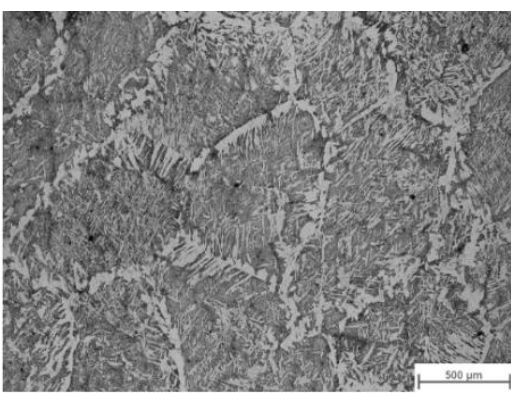

(c)

Figure 2 Etched samples of steel number 1 tested at (a) $900{ }^{\circ} \mathrm{C}$, (b) $750^{\circ} \mathrm{C}$ and (c) $650^{\circ} \mathrm{C}$ 
Images from microstructure of steel number 2 are shown in Figure 3. With its better ductility, this steel also presented signs of recrystallization above $900{ }^{\circ} \mathrm{C}$, with elongated grains and clear ductile fracture through the sample, indicating that the deformation was not concentrated at grain boundaries. From 850 to $750{ }^{\circ} \mathrm{C}$ some areas with larger grains and brittle fracture were seen, but also areas with elongated grains and ductile fracture were present and predominating. At $700^{\circ} \mathrm{C}$ (lowest ductility), elongated grains were not seen and some ferrite at grain boundaries was identified, aligned with the lower ductility seen at this point. Below this temperature, more deformation induced ferrite inside the grains was seen to be formed, what brings a better strain distribution through the grain, and not only at the boundary, improving the ductility again, as seen in Figure 1.

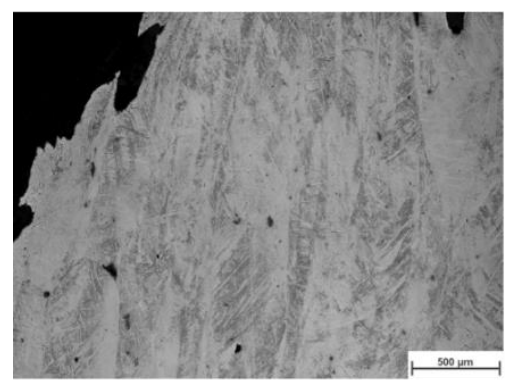

(a)

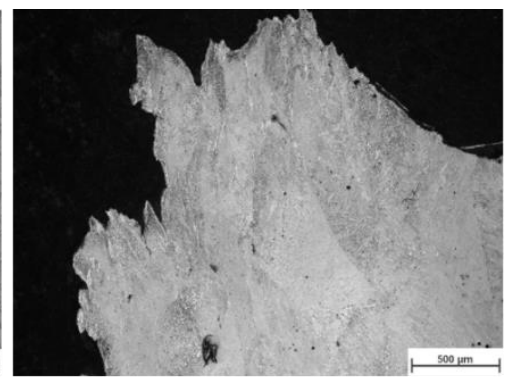

(b)

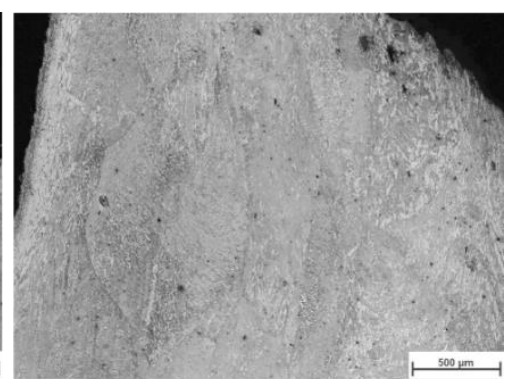

(c)

Figure 3 Etched samples of steel number 2 tested at (a) $900{ }^{\circ} \mathrm{C}$, (b) $700{ }^{\circ} \mathrm{C}$ and (c) $650^{\circ} \mathrm{C}$

The difference in ductility at lower temperatures is clearly seen in the fracture and microstructure when comparing the structures seen for both steels. While steel number 1 shows a clear difference in the grains when the temperature reaches the ductility minimum, steel number 2 had a similar structure throughout the tested samples, with some minor differences only. This relates to the differences seen between the two ductility curves presented.

The results of the precipitation kinetics simulation for steel number 1 are displayed in Table 2. They show that AIN at grain boundaries are expected to be the bigger precipitates, but in lower fraction. MnS at dislocations had the highest phase fraction, with a smaller mean radius. Furthermore, a decrease of mean radius and an increase of number density with the decrease of temperature was seen for all precipitates, together with a slight decrease in phase fraction at $800{ }^{\circ} \mathrm{C}$. This indicates a stronger influence of the change in grain size in the fraction of the precipitates in the material. This difference in results between both temperatures is due to the coarsening and growth of precipitates that occurs when the temperature is higher. Finer precipitates are known to be detrimental to ductility [16], matching the drop in ductility seen from $900{ }^{\circ} \mathrm{C}$ to $800{ }^{\circ} \mathrm{C}$. The dislocation density results were lower for the higher temperature, which is due to the annihilation of dislocations. This can also be linked to the experimental results, since with lower dislocation density there is also less sites for precipitation, improving the ductility.

Table 2 Results of the simulated precipitation kinetics for steel number 1

\begin{tabular}{|c|c|c|c|c|c|c|c|}
\hline \multirow{2}{*}{ Steel 1 } & & \multicolumn{2}{|c|}{ Mean Radius (nm) } & \multicolumn{2}{c|}{ Number Density $\left(\mathbf{m}^{-3}\right)$} & \multicolumn{2}{c|}{ Phase Fraction (\%) } \\
\hline & Location & $\mathbf{8 0 0}{ }^{\circ} \mathbf{C}$ & $\mathbf{9 0 0 ^ { \circ } \mathbf { C }}$ & $\mathbf{8 0 0}{ }^{\circ} \mathbf{C}$ & $\mathbf{9 0 0}^{\circ} \mathbf{C}$ & $\mathbf{8 0 0}^{\circ} \mathbf{C}$ & $\mathbf{9 0 0 ^ { \circ } \mathbf { C }}$ \\
\hline \multirow{2}{*}{ MnS } & $\mathrm{d}$ & 8.17 & 20.99 & $6.31 \mathrm{E}+19$ & $4.32 \mathrm{E}+18$ & $1.57 \mathrm{E}-02$ & $1.75 \mathrm{E}-02$ \\
\hline \multirow{2}{*}{ AIN } & gb & 60.35 & 81.66 & $7.09 \mathrm{E}+11$ & $5.46 \mathrm{E}+11$ & $6.53 \mathrm{E}-08$ & $1.25 \mathrm{E}-07$ \\
\cline { 2 - 9 } & MnS & 2.54 & 6.75 & $6.35 \mathrm{E}+19$ & $3.91 \mathrm{E}+18$ & $4.52 \mathrm{E}-04$ & $6.18 \mathrm{E}-04$ \\
\hline
\end{tabular}


Simulations for steel number 2, presented in Table 3, showed that very little change in the precipitates is expected to be seen between 900 and $800{ }^{\circ} \mathrm{C}$. The exception was $\mathrm{Ti}(\mathrm{C}, \mathrm{N})$ at dislocations, showing a coarsening with the increase of temperature (higher mean radius with lower number density and constant phase fraction). This is in good agreement with the experimental results seen, where the ductility is high and very similar at these temperatures. BN showed higher results of mean radius than $\mathrm{Ti}(\mathrm{C}, \mathrm{N})$, but lower number density, endorsing that TiN are preferentially formed, consuming part of the nitrogen available before BN can be formed. This behavior also contributes to a better ductility of the steel. The lower fraction of precipitates at grain boundaries also shows a reason for the improvement in ductility and reinforces that the dispersive precipitation of TiN can reduce the number of precipitates at grain boundaries, avoiding the pining effect.

Table 3 Results of simulated precipitation kinetics of steel number 2

\begin{tabular}{|c|c|c|c|c|c|c|c|}
\hline \multirow[t]{2}{*}{ Steel 2} & \multirow[b]{2}{*}{ Location } & \multicolumn{2}{|c|}{ Mean Radius (nm) } & \multicolumn{2}{|c|}{ Number Density $\left(\mathrm{m}^{-3}\right)$} & \multicolumn{2}{|c|}{ Phase Fraction (\%) } \\
\hline & & $800{ }^{\circ} \mathrm{C}$ & $900^{\circ} \mathrm{C}$ & $800^{\circ} \mathrm{C}$ & $900^{\circ} \mathrm{C}$ & $800^{\circ} \mathrm{C}$ & $900^{\circ} \mathrm{C}$ \\
\hline \multirow{2}{*}{ BN } & $\mathrm{gb}$ & 1155.76 & 1155.44 & $2.03 E+09$ & $2.03 E+09$ & $1.32 \mathrm{E}-06$ & $1.31 \mathrm{E}-06$ \\
\hline & $d$ & 356.44 & 389.71 & $1.08 E+15$ & $9.73 E+14$ & 2.44E-02 & 2.44E-02 \\
\hline \multirow{2}{*}{$\mathrm{Ti}(\mathbf{C}, \mathbf{N})$} & $\mathrm{gb}$ & 112.08 & 112.72 & $3.77 \mathrm{E}+11$ & $3.77 E+11$ & 2.23E-07 & 2.26E-07 \\
\hline & $d$ & 2.51 & 14.58 & $1.47 \mathrm{E}+19$ & $2.18 \mathrm{E}+18$ & 4.99E-03 & $5.88 \mathrm{E}-03$ \\
\hline & & \multicolumn{3}{|c|}{$800^{\circ} \mathrm{C}$} & \multicolumn{3}{|c|}{$900^{\circ} \mathrm{C}$} \\
\hline \multicolumn{2}{|c|}{ Dislocation Density } & \multicolumn{3}{|c|}{$6.77 \mathrm{E}+13$} & \multicolumn{3}{|c|}{$3.95 E+13$} \\
\hline
\end{tabular}

On comparing the results from both steels, it can be seen that the precipitates are coarser and in lower number density in steel number 2, which may also be a reason for the improvement in ductility for steel number 2, since coarser precipitates are less detrimental. Furthermore, AIN and MnS can have a more negative effect on the ductility than the nitrides seen for steel number 2.

\section{CONCLUSION}

The comparison between the two low alloyed steels showed that the addition of $\mathrm{Cr}$, $\mathrm{Ni}$ and specially $\mathrm{B}$ and $\mathrm{Ti}$ improved the hot ductility behavior of the steel. This improvement can be attributed to the lower $\mathrm{S}$ content; the absence of AIN, since TiN and BN are preferentially formed; the earlier and dispersed precipitation of TiN allowing less $\mathrm{BN}$ to be formed at grain boundaries; together with less deformation induced ferrite films formation.

This general improvement in the hot ductility behavior of the steel through the addition of alloying elements as presented is interesting for the continuous casting process. It can decrease cracks during the process, improving quality and reducing process costs.

\section{ACKNOWLEDGEMENTS}

The authors gratefully acknowledge the funding support of K1-MET GmbH, metallurgical competence center. The research program of the K1-MET competence center is supported by COMET

(Competence Center for Excellent Technologies), the Austrian program for competence centers.

COMET is funded by the Federal Ministry for Climate Action, Environment, Energy, Mobility, Innovation and Technology, the Federal Ministry for Digital and Economic Affairs, the Federal States of Upper Austria, Tyrol, and Styria as well as the Styrian Business Promotion Agency (SFG) and the Standortagentur Tyrol. Furthermore, Upper Austrian Research GmbH continuously support K1-MET. Beside the public funding from COMET, this research project is partially financed by the scientific 


\section{partners Graz University of Technology, Montanuniversität Leoben, TU Wien, and the industrial partners Primetals Technologies Austria and voestalpine Stahl.}

\section{REFERENCES}

[1] CHOWN, L.H. The influence of continuous casting parameters on hot tensile behaviour in low carbon, niobium and boron steels. Johannesburg, 2008. Dissertation. University of Witwatersrand.

[2] HUITRON, R.M.P., LOPEZ, P.E.R., VUORINEN, E., JENTNER, R., KÄRKKÄINEN, M.E. Converging criteria to characterize crack susceptibility in a micro-alloyed steel during continuous casting. Materials Science and Engineering A. 2020, vol. 772, 138691.

[3] MINTZ, B., CROWTHER, D.N. Hot ductility of steels and its relationship to the problem of transverse cracking in continuous casting. International Materials Reviews. 2010, vol. 55, pp. 168-196.

[4] ZARANDI, F., YUE, S. The effect of boron on hot ductility of Nb-microalloyed steels. ISIJ International. 2006, vol. 46, pp. 591-598.

[5] MINTZ, B., YUE, S., JONAS, J.J. Hot ductility of steels and its relationship to the problem of transverse cracking during continuous casting. International Materials Reviews. 1991, vol. 36, pp. 187-220.

[6] BANKS, K.M., TULING, A., MINTZ, B. Influence of thermal history on the hot ductility of steel and its relationship to the problem of cracking in continuous casting. Materials Science and Technology. 2012, vol. 28, pp. 536-542.

[7] MEJÍA, I., ALTAMIRANO, G., BEDOLLA-JACUINDE, A., CABRERA, J.M. Effect of Boron on the hot ductility behavior of a low carbon advanced ultra-high strength steel (A-UHSS). Metallurgical and Materials Transactions A. 2013, vol. 44A, pp. 5165-5176.

[8] GONTIJO, M., HOFLEHNER, C., ILIE, S., SIX, J., SOMMITSCH, C. Holding time influence on the hot ductility behavior of a continuously cast low alloy steel. Metals. 2021, vol. 11, p. 64.

[9] KOZESCHNIK, E. MatCalc Version 6.02 (Database mc_fe_v2.060). Available from: http://matcalc.tuwien.ac.at/

[10] LÜCKL, M., WOJCIK, T., POVODEN-KARADENIZ, E., ZAMBERGER, S., KOZESCHNIK, E. Co-precipitation behavior of MnS and AIN in a low-carbon steel. Steel Research International. 2017, vol. 89, p. 1700342.

[11] SUN, W.P., MILITZER, M., JONAS, J.J. Strain-induced nucleation of MnS in electrical steels. Metallurgical Transactions A. 1992, vol. 23A, pp. 821-830.

[12] WANG, W.S., ZHU, H.Y., SUN, J., LEI, J.L., DUAN, Y.Q., WANG, Q. Thermodynamic analysis of BN, AIN and TiN precipitation in Boron-bearing steel. Metalurgija. 2019, vol. 58, pp. 199-202.

[13] NAGATA, M.T., SPEER, J.G., MATLOCK, D.K. Titanium nitride precipitation behavior in thin-slab cast highstrength low-alloy steels. Metallurgical and Materials Transactions A. 2002, vol. 33A, pp. 3099-3110.

[14] LIU, W.-J., LI, J., SHI, C.-B., HUO, X.-D. Effect of boron and titanium addition on the hot ductility of low-carbon Nb-containing steel. High Temperature Materials and Processes. 2015, vol. 34, pp. 813-820.

[15] CHO, K.C., MUN, D.J., KANG, M.H., LEE, J.S., PAR, J.K., KOO, Y.M. Effect of thermal cycle and nitrogen content on the hot ductility of boron-bearing steel. ISIJ International. 2010, vol. 50, pp. 839-846.

[16] COMINELI, O., ABUSHOSHA, R., MINTZ, B. Influence of titanium and nitrogen on hot ductility of C-Mn-Nb-AI steels. Materials Science and Technology. 1999, vol. 15, pp. 1058-1068.

[17] ABUSHOSHA, R., VIPOND, R., MINTZ, B. Influence of titanium on hot ductility of as cast steels. Materials Science and Technology. 1991, vol. 7, pp. 613-621

[18] LEWIS, J., JONAS, J.J., MINTZ, B. The deformation induced ferrite during mechanical testing. ISIJ International. 1998, vol. 38, pp. 300-309. 